\title{
Performed Activity Study Day Range
}

National Cancer Institute

\section{Source}

National Cancer Institute. Performed Activity Study Day Range. NCI Thesaurus. Code C95367.

The relative timing for a performed activity expressed as the number of days offset from the study-defined reference activity (e.g. date of registration, start of treatment).

(BRIDG) 